\title{
Phenological Classification Using Deep Learning and the Sentinel-2 Satellite to Identify Priority Afforestation Sites in North Korea
}

\author{
Joon Kim ${ }^{1} \mathbb{D}$, Chul-Hee $\operatorname{Lim}^{2,+} \mathbb{D}$, Hyun-Woo Jo ${ }^{1}$ and Woo-Kyun Lee ${ }^{3,4, * \mathbb{D}}$ \\ 1 Department of Environmental Science and Ecological Engineering, Korea University, Seoul 02841, Korea; \\ rlawns0213@korea.ac.kr (J.K.); endeavor4_a1@korea.ac.kr (H.-W.J.) \\ 2 College of General Education, Kookmin University, Seoul 02707, Korea; clim@kookmin.ac.kr \\ 3 Division of Environmental Science and Ecological Engineering, Korea University, Seoul 02841, Korea \\ 4 OJEong Resilience Institute (OJERI), Korea University, Seoul 02841, Korea \\ * Correspondence: leewk@korea.ac.kr \\ + Equal contribution to the corresponding authorship goes to this author.
}

check for updates

Citation: Kim, J.; Lim, C.-H.; Jo, H.-W.; Lee, W.-K. Phenological Classification Using Deep Learning and the Sentinel-2 Satellite to Identify Priority Afforestation Sites in North Korea. Remote Sens. 2021, 13, 2946. https://doi.org/10.3390/rs13152946

Academic Editor: Wenquan Zhu

Received: 18 June 2021

Accepted: 25 July 2021

Published: 27 July 2021

Publisher's Note: MDPI stays neutral with regard to jurisdictional claims in published maps and institutional affiliations.

Copyright: (C) 2021 by the authors. Licensee MDPI, Basel, Switzerland. This article is an open access article distributed under the terms and conditions of the Creative Commons Attribution (CC BY) license (https:/ / creativecommons.org/licenses/by/ $4.0 /)$.

\begin{abstract}
The role of forests to sequester carbon is considered an important strategy for mitigating climate change and achieving net zero emissions. However, forests in North Korea have continued to be cleared since the 1990s due to the lack of food and energy resources. Deforestation in this country has not been accurately classified nor consistently reported because of the characteristics of small patches. This study precisely determined the area of deforested land in North Korea through the vegetation phenological classification using high-resolution satellite imagery and deep learning algorithms. Effective afforestation target sites in North Korea were identified with priority grade. The U-Net deep learning algorithm and time-series Sentinel-2 satellite images were applied to phenological classification; the results reflected the small patch-like characteristics of deforestation in North Korea. Based on the phenological classification, the land cover of the country was classified with an accuracy of $84.6 \%$; this included 2.6 million ha of unstocked forest and reclaimed forest. Sites for afforestation were prioritized into five grades based on deforested characteristics, altitude and slope. Forest area is expanded and the forest ecosystem is restored through successful afforestation, this may improve the overall ecosystem services in North Korea. In the long term, it will be possible to contribute to carbon neutrality and greenhouse gas reduction on the Korean Peninsula level through optimal afforestation by using these outcomes.
\end{abstract}

Keywords: landcover classification; vegetation phenology; afforestation; deforestation; North Korea; deep learning

\section{Introduction}

With accelerating climate change, many countries have declared their goal of carbon neutrality. The success of mitigation initiatives is dependent on the long-term net balance between carbon gains and losses [1]. From a carbon-neutral perspective, it is very important to estimate carbon uptake and emissions based on land cover. It is possible to estimate carbon emissions and absorption by establishing a land cover map and tracking changes through continuous mapping. Forests play an important role in the global carbon cycle and are thus valued worldwide for the array of ecosystem services they provide to society [2]; this includes the sequestration or emission of carbon, one of the major greenhouse gases [3]. Forests take up atmospheric carbon dioxide during photosynthesis, using the gas to produce sugar and other organic compounds [4]; this process facilitates carbon sequestration function. The amount of carbon uptake in forests varies depending on the climate, and forest physiognomy and age. For example, forests that are 30 years of age in South Korea take up more than $10 \mathrm{t} / \mathrm{ha}$ of carbon annually [5]. The forested area of South Korea is approximately 6.3 million ha [6], sequestering 67.91 million $t$ of carbon. North Korea, also 
located on the Korean Peninsula, features climate, environment, and forested area ratios similar to those of South Korea. In the 1980s, South Korea conducted the first analysis of the forested areas in North Korea using Landsat-5 satellite imagery in the 1980s; the forest area was calculated to exceed 9 million ha [7]. Based on this calculation, the annual amount of carbon absorbed by forests in North Korea is estimated at 97.02 million t. The annual average carbon emissions in South Korea is 727 million $t$ [8], which constitutes approximately $1.3 \%$ of the global carbon emissions. The carbon absorption by North Korean forests in the 1970s was estimated to be $13 \%$ of the emissions released from South Korea [9]. In terms of the net zero objective, one of the most significant climate change response goals, forest resources are a very important carbon sink. As such, the carbon absorption function of forests must be maintained through informed management and protection. However, forests in North Korea are continually being destroyed; between 2001 and 2019, approximately 233,000 ha of forest were cleared [10].

Researchers have been attempting to classify land cover in North Korea, including studies from the Ministry of Environment of the Republic of Korea. This classification was conducted by combining satellite images and field survey information. For North Korea, this dependence on satellite imagery is high as a result of its inaccessibility [11]. For this reason, land cover classification results may vary depending on the satellite image resolution and the time that the image was acquired [12]; this has produced differences in the classification results between studies. These studies have mainly used imagery acquired from the Moderate Resolution Imaging Spectroradiometer (MODIS) and Landsat5 satellites [13-15]. As the spatial resolution of satellite imagery is $250 \times 250 \mathrm{~m}^{2}$ and $30 \times 30 \mathrm{~m}^{2}$, it was difficult to reflect the deforestation characteristics in North Korea, and the classification accuracy was poor.

Since 2012 when Kim Jong-un commenced his reign, North Korea has been attempting various afforestation projects [16]; however, the afforestation areas generated through these efforts are narrower than deforested areas [17]. Additionally, there has been an absence of continuous reporting or monitoring on afforestation performance, and the exact area of forested land has not been officially released by North Korea. For this reason, no studies have been able to measure nor monitor the exact amount of forest resources in North Korea. Although some studies make attempts, these estimates are updated infrequently (e.g., 10 y), similar to the classification results from the Republic of Korea. [18]. Therefore, a more accurate classification of land cover in North Korea is necessary to protect and restore its forest resources. In addition to the existing classification system, an effective restoration plan should be established based on the classification of deforestation reflecting its characteristics.

Human activities, such as securing resources, are largely responsible for deforestation in North Korea, as opposed to natural disasters [19]. As such, it gradually progresses from easy to access low-altitude areas, to high-altitude areas [20]. During deforestation, timber felling is performed to secure energy resources; subsequently, land is reclaimed to secure food resources. Therefore, deforestation primarily involves reclamation of land and its conversion from forests to agricultural lands, and unstocked forest that make up less than $30 \%$ of the crown area [6,21]. As reclaimed forest and unstocked forest are created by human activities, they are observed along hillsides and slopes, which delineate the boundaries between agricultural land and forest. As ongoing deforestation in North Korea occurs in small patches, the use of high-resolution satellite imagery is necessary for analysis. Most regions within North Korea, excluding Pyongyang, have difficulty securing energy and food resources [22]; this has led to nationwide anthropogenic deforestation. Therefore, it is necessary to classify nationwide deforestation using satellite imagery and determine the amount of forest resources and the area of deforestation in North Korea.

Land cover classification using satellite imagery may be carried out using the differences in land cover values as per the satellite imagery [23]. Typically, researchers use differences in the values according to the wavelength band acquired by the satellite image. They also utilize the multi-environment index which is calculated using satellite 
imagery [24]. However, if a single-period satellite image is used, the classification result may differ depending on the time when the image was acquired, even at the same location [25]. For satellite imagery acquired during winter is problematic as it does not recognize the difference between agricultural land and barren. The Korean Peninsula, where North Korea is located, experiences four distinct seasons, and where most land cover consists of vegetation; as such, the phenological characteristics of vegetation are very well represented [26]. If these characteristics are used during the classification process, it enables the compensation of errors in the classification results that occur with the use of single-period satellite imagery [25]. To accurately capture the vegetation phenological characteristics, satellite images of at least four or more scenes must be used to reflect all characteristics across all seasons; this necessitates the use of a large amount of data in the analysis. For analysis, the satellite image classification may be effectively and accurately carried out using an artificial intelligence deep learning U-Net algorithm; this has recently attracted considerable research attention $[27,28]$.

This study employed U-Net-based deep learning for land cover classification, including deforestation, for North Korea by reflecting the phenological characteristics of vegetation and utilizing Sentinel-2 satellite imagery with $10 \mathrm{~m}$ spatial resolution. The usage of Sentinel-2 satellite imagery allows to accurately analyze the small patch-like deforestation occurring in North Korea. Through the derivation of satellite imagery from across North Korea that reflects the phenological characteristics of vegetation, it is possible to effectively classify land cover. However, there is a large amount of available data from the phenological Sentinel-2 satellite imagery spanning North Korea, forming a type of Big Data. Deep learning has been hugely successful in Big Data analysis; as such, it may be a good candidate to capitalize on the potential of such complex and massive data [29]. The U-Net deep learning algorithm performs well in the classification of satellite imagery [30]. As the exact deforested area in North Korea has not yet been derived, and forest restoration has not been consistently effective, it is necessary to identify exact deforestation status and establish an evidence-based forest restoration plan for recovering ecosystem services and forest environment [31,32]. This means that optimal sites for afforestation in North Korea need to be derived by using accurate deforestation data. Effective forest restoration, based on graded afforestation target data, should be promoted to restore and manage forest resources in the country [33]. This data may form the basis forest cooperation between the international community and North Korea.

\section{Study Area}

North Korea is located in East Asia, between $37^{\circ} 41^{\prime} 00^{\prime \prime} \mathrm{N}$ and $43^{\circ} 00^{\prime} 36^{\prime \prime} \mathrm{N}$ (latitude), and $124^{\circ} 18^{\prime} 41^{\prime \prime} \mathrm{E}$ and $130^{\circ} 41^{\prime} 32^{\prime \prime} \mathrm{E}$ (longitude); it occupies the northern part of the Korean Peninsula (Figure 1). North Korea spans an area of $12,054,000$ ha, in which $80 \%$ of its territory is mountainous. The administrative districts of the country consist of nine provinces, one capital city, and three special cities. The country has an average altitude above sea level of $\sim 40 \mathrm{~m}$, including plateaus above $2000 \mathrm{~m}$ in altitude. The terrain in North Korea may be characterized as being high in the east and low in the west. The country is located in a mid-latitude ecotone, characterized by a temperate climate and four distinct seasons; this has created clearly observable phenological characteristics in the vegetation of North Korea. In North Korean, rice planting and sowing is usually come in June to July. And then crops are harvested in September to October. Phenological characteristics of vegetation is appeared by distinct season and agricultural characteristics.

Previously, the mountainous regions of North Korea were forested, accounting for $60 \%$ of forested area in the entire Korean Peninsula; however, the current forest cover has been decreasing [34]. The principal reason for this deforestation is the lack of energy and food resources [35]. In North Korea, the lack of an established energy infrastructure forces the residents to use forest resources, including firewood, for energy. The lack of food also creates the demand for more agricultural land, in which forested land is reclaimed after felling timber for firewood. For this reason, North Korea has been undergoing gradual 
deforestation, beginning with the forests in low altitude areas. The Food and Agriculture Organization of the United Nations (FAO) has reported that since the 1990s, 12\% of the forests in North Korea have been cleared [36]. North Korea has been attempting to resolve its energy and food issues to protect its forest resources [36]; as a part of this effort, they conducted 'Agroforestry Management,' to reclaim land with slopes $<15^{\circ}$ and afforest land on slopes $>15^{\circ}$ in the mountain region. Since 2012 when Kim Jong-un commenced his reign, North Korea has considered that forest-related policies have sufficient importance to consider these issues a "forest restoration battle;" as such, there has been emphasis for these issues to be included in various propaganda materials $[35,36]$.

Although North Korea claims that afforestation is being implemented, its rate of deforestation is much faster than afforestation. In attempting to identify the results of these afforestation efforts using Google Earth Pro (GEP), this study identified a small area in Pyongyang special city (Figure 2). The area of the afforested patch in Figure 2 is approximately 3 ha and its altitude ranges from 110 to $158 \mathrm{~m}$; the surrounding area was barren, reclaimed forest.

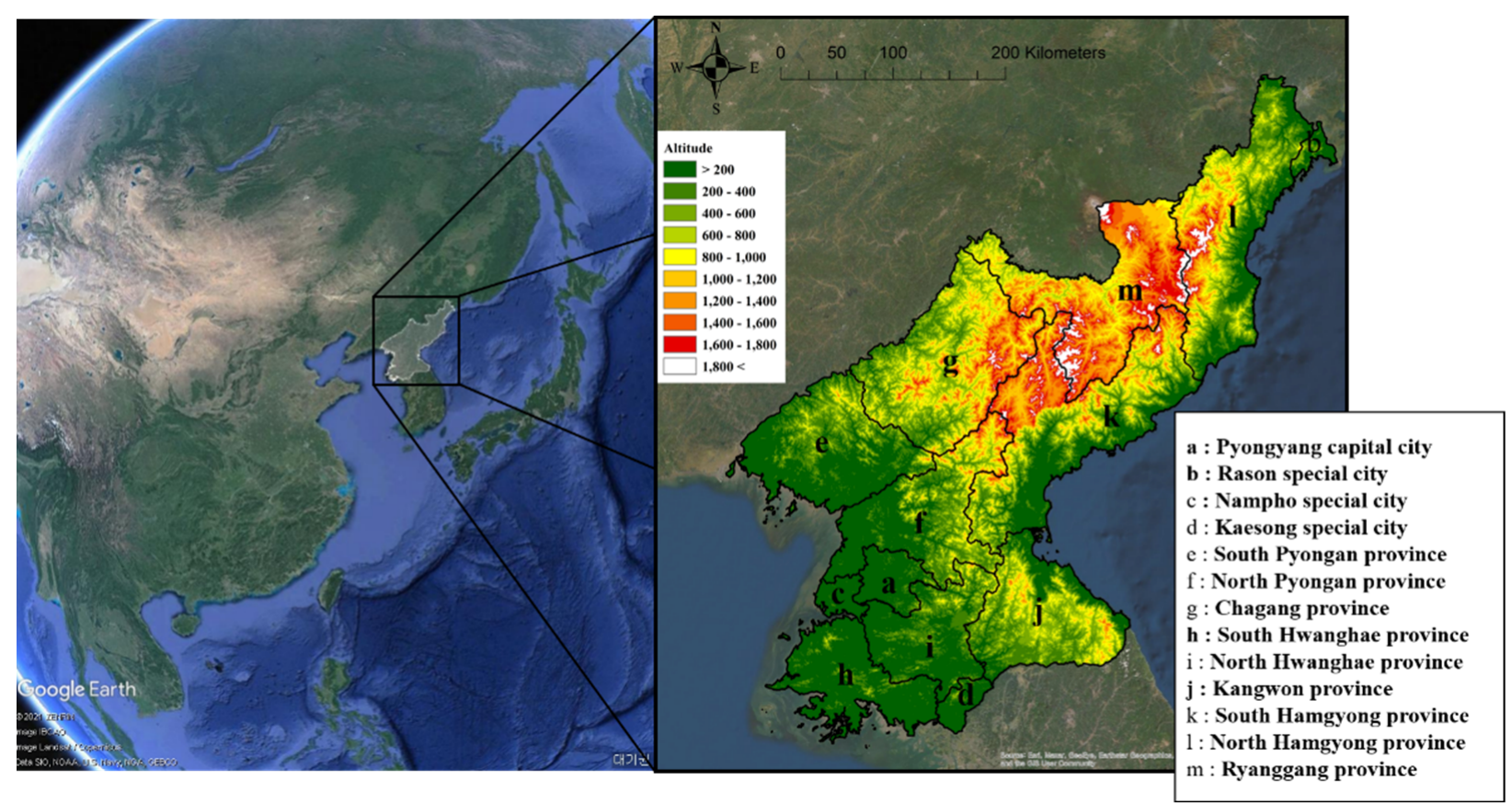

Figure 1. Study area: the administrative boundaries and elevations in North Korea.

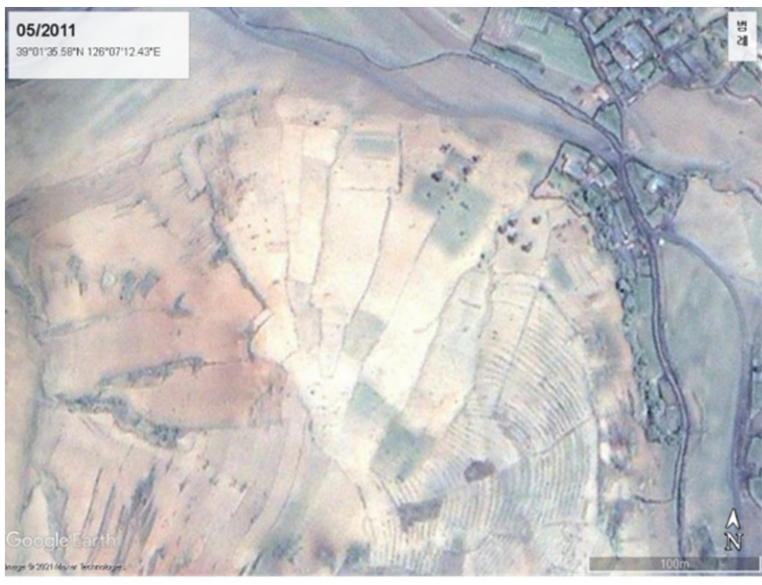

(a)

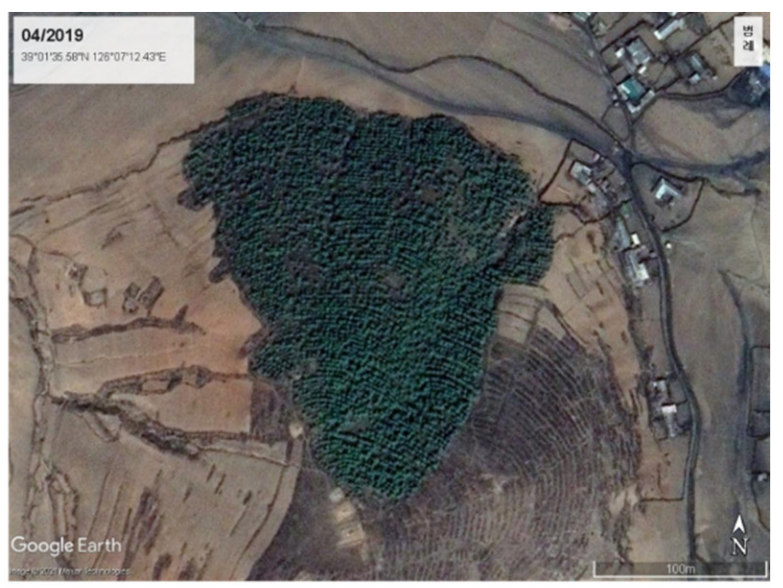

(b)

Figure 2. Afforestation site in North Korea (39 $\left.01^{\prime} 35.58^{\prime \prime} \mathrm{N}, 126^{\circ} 07^{\prime} 12.43^{\prime \prime} \mathrm{E}\right)$ : (a) May 2011; and (b) April 2019. 


\section{Materials and Methods}

\subsection{Sentinel-2 Data Collection and Processing}

Bi-monthly vegetation greenness data spanning North Korea is required for North Korea when using the phenological characteristics of vegetation; this data is made up of Sentinel-2 satellite imagery. This study uses the normalized difference vegetation index (NDVI) as the vegetation greenness indicator, in which the vegetation vitality was determined based on the difference between the red and near infrared (NIR) bands from the satellite imagery. As the spatial resolution of the red, green, blue, and NIR bands from the Sentinel-2 satellite is $10 \mathrm{~m}$, this same spatial resolution was established for the NDVI derived from the Sentinel-2. The NDVI was calculated using Equation (1):

$$
\mathrm{NDVI}=\frac{\mathrm{NIR}+\text { Red }}{\mathrm{NIR}-\operatorname{Red}}
$$

To calculate the NDVI, basic data processing of Sentinel-2 satellite imagery was performed using the Google Earth Engine (GEE). The swath width of Sentinel-2 satellite imagery is $290 \mathrm{~km}$, provided with swath shaped linear image, cut into squares. As one swath cannot cover full North Korea, several scenes were selected. Of the Sentinel-2 satellite imagery acquired by GEE after March 2018, the image with the least cloud cover was mosaiced. The NDVI image was calculated by applying the NDVI formula to the band 4 (red) and band 8 (NIR) of the selected satellite imagery. Then maximum value of NDVI is composited between selected satellite images for reflecting representative vegetation greenness. From this process, six bi-monthly NDVI images were generated from March, 2018 to February, 2019 using images with the fewest clouds (Figure 3). Of the NDVI image results, some were excluded from analysis (i.e., Figure $3 \mathrm{f}$ ), as the NDVI was not normally expressed in the snow-covered area. The NDVI outputs indicated differences in the seasonal NDVI values across North Korea. This is based on the difference in the seasonal NDVI characteristics of vegetation; Figure $3 a, b$ are before rice planting and sowing, that some area has low value of NDVI. However, in Figure 3c, the general value of NDVI is high over the territory. This shows that the NDVI difference according to landcover is distinct within the scenes, during vegetation growth, sow, harvest, and leaf fall. Thus, Figure 3a-e were stacked into one multi-band NDVI image using the 'composite band' tool in ESRI ArcGIS software. Each band of result is comprised of Figure 3a-e. The multi-band NDVI image was able to reflect difference in the NDVI values for each scene with respect to the coordinates. Multi-band satellite image can be displayed via red-green-blue (RGB) color combination. Multi-band NDVI image also demonstrate color differences based on land cover according to NDVI value difference over time periods (Figure 4). In Figure 4, red area is supposed as agricultural land, because agricultural land has high value of NDVI only in Jul-Aug, 2018 band, after sowing. Land cover is identified using GEP by visually comparing Figure 4 and GEP satellite images according to color of Figure 4.

\subsection{Classification Using U-Net Based Algorithm}

The U-Net algorithm is a deep convolutional neural network (CNN), first introduced in biomedical image segmentation by Olaf et al. [37]; it has since been used in many segmentation tasks. U-Net, being one form of segmentation, can be used for land cover classification using satellite imagery. The U-Net algorithm is operated by supervised training, requiring ground truth labeled dataset for modeling. This study mapped the land cover of North Korea based on stepwise classification using the U-Net algorithm; this is a multiple, single-class segmentation. 


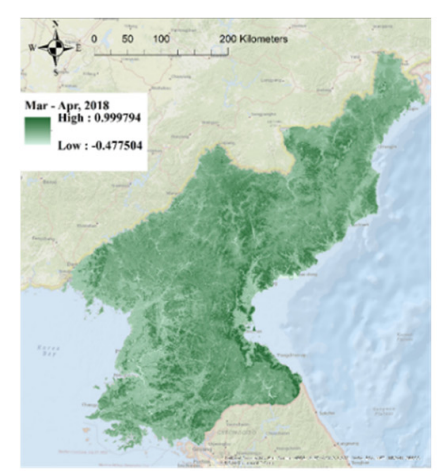

(a)

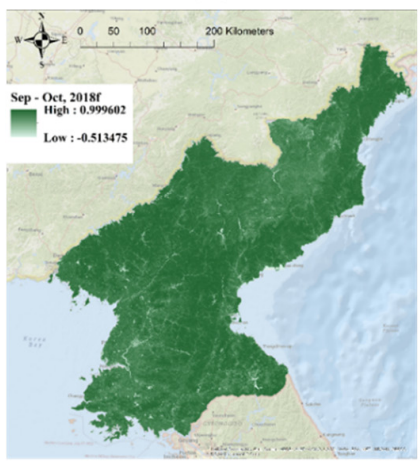

(d)

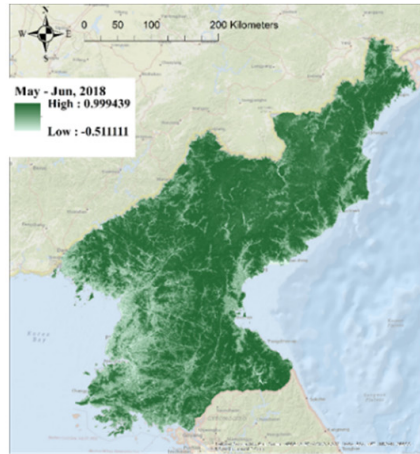

(b)

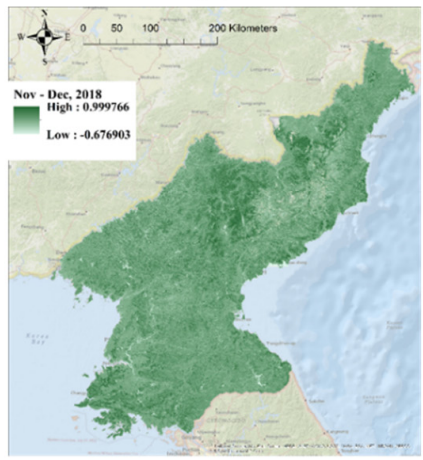

(e)

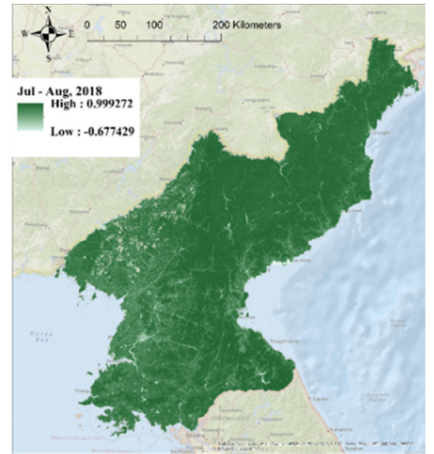

(c)

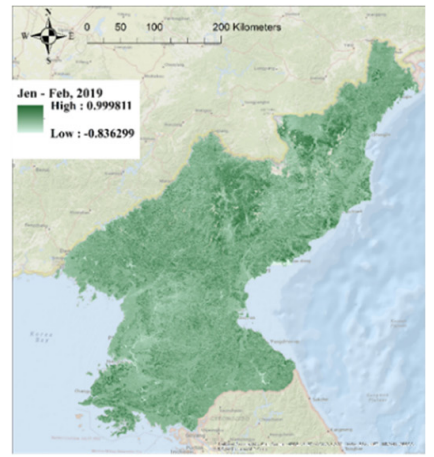

(f)

Figure 3. Mosaiced time series NDVI imagery: (a) March-April 2018; (b) May-June 2018; (c) July-August 2018; (d) September-October 2018; (e) November-December 2018; and (f) JanuaryFebruary 2019.

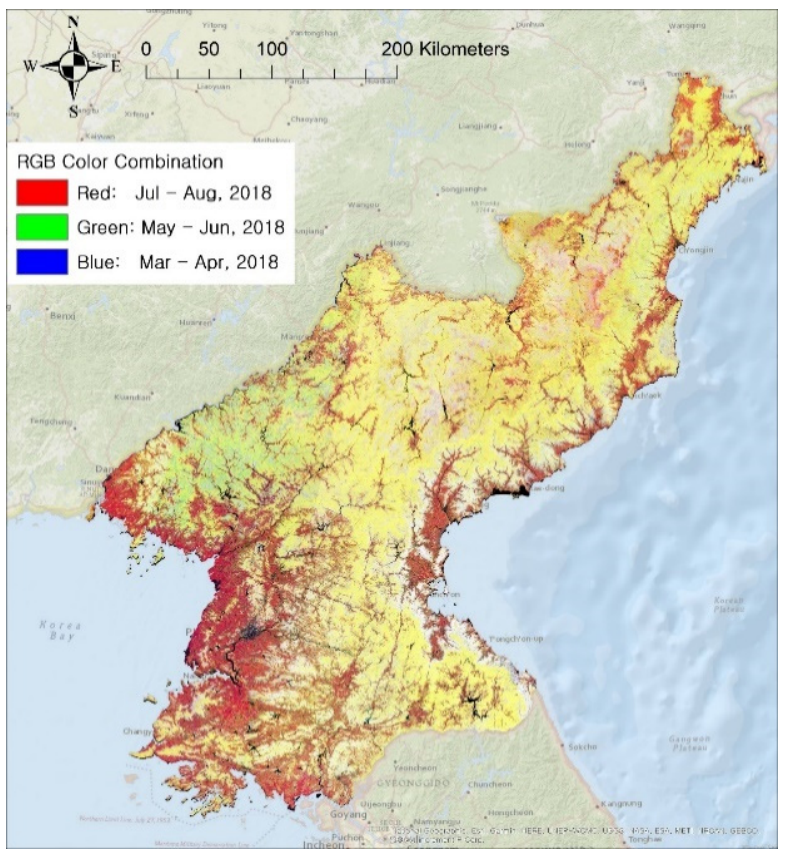

Figure 4. RGB Color Combination Visualization of Multi-band NDVI.

Five scenes of training data for U-Net were extracted from multi-band NDVI images, which were $20 \times 20 \mathrm{~km}$ in size. Each scene is extracted from five different provinces to minimize data differences due to variations in latitude and longitude. Since there is no ground truth data, that could be referenced for generating labeled dataset, the 'Band thresholding' method was used to generate pseudo labeling data, which enables to use 
unlabeled data for training with a limited amount of labeled data. Among the five NDVI bands of multi-band NDVI images, one with binary NDVI distributions was used for thresholding (in the case of first classification, May-June 2018 layer was used, because that period is before sowing, so that NDVI difference between mountain region and nonmountain region is distinct). Threshold is set on the point of inflection or dividing the histogram into two according to Otsu's method [38]; then, the setting range was confirmed by visual interpretations on randomly distributed inspection points in the target area. Figure 5 presents the training data from Pyeongyang Province and the forest labeling process using L3Harris ENVI software; Figure 5a is the histogram of May-June 2018 layer of Figure $5 b$ and band thresholding parameters, and Figure 5b,c are training data and labeled data. In Figure 5b, forests were distinguished by color as light yellow and fully covered by green color in Figure 5c. This process enabled U-Net model to learn seasonal NDVI characteristics of training data (in the case of Figure 5, NDVI characteristics of forest). ENVI software automatically separates input training data to $80 \%$ of training data and $20 \%$ of validation data and shuffle.

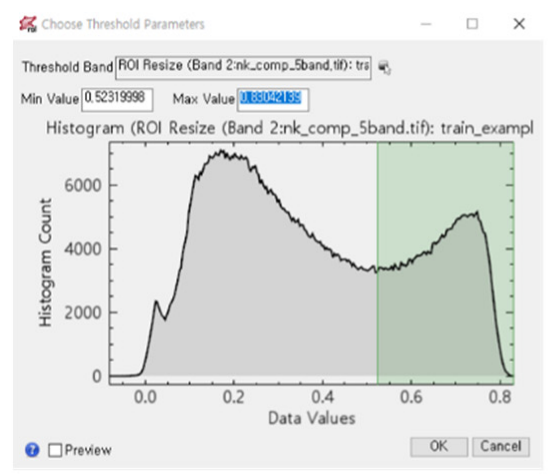

(a)

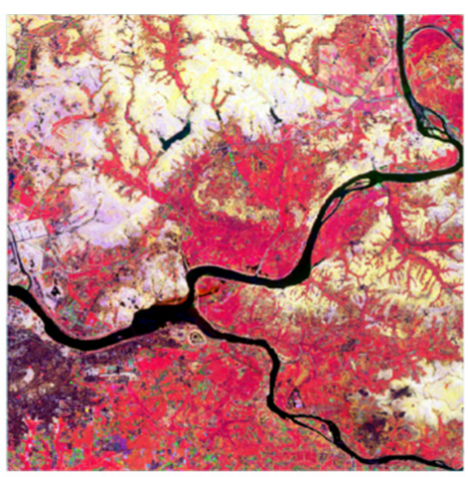

(b)

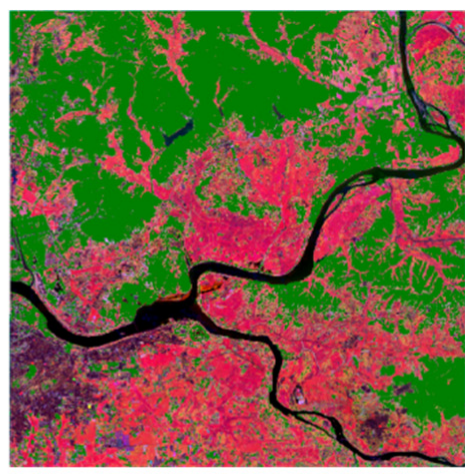

(c)

Figure 5. Deep learning labeling tool and training data: (a) band threshold setting tool; (b) training raster data; and (c) forest labeled raster data.

Although U-Net is a type of semantic segmentation that can perform multi-class classification, stepwise classification was conducted to improve the data processing efficiency. Figure 6 presents the stepwise classification process, in which the full scene is initially classified into mountain and non-mountain regions, and then further divided from nonmountain region to vegetation cover and non-vegetation cover. Vegetation cover may be categorized into agricultural region and reclaimed forest. The non-vegetation region was not clearly classified as the used area and water, as there were very small NDVI differences between these two categories. The forest was classified as either an evergreen or deciduous forest, in which the NDVI difference for leaf growth and winter season were elucidated using the Mar-Apr and Nov-Dec layers from Figure 3. Time series multi-band NDVI imagery were classified into seven scenes using a six-time classification and six different CNN models.

\subsection{Identifying Priority Afforestation Sites Using Topographic Data}

One of key geographic features in North Korea is the distribution of highlands at an altitude of $2000 \mathrm{~m}$. These highlands occur at altitudes higher than the tree limit layer, and alpine vegetation occur above the tree limit layer. A previous study reported that alpine vegetation is distributed at altitudes between 1900 and $2000 \mathrm{~m}$ above sea level (asl) [39]. To extract the alpine region, Shuttle Radar Topography Mission (SRTM) Digital Elevation Model (DEM) was used; this has a spatial resolution of 1-ARC $(\sim 30 \mathrm{~m})$. The SRTM DEM imagery were provided by USGS, by $1^{\circ}$ tiles. All tiles on the Korean Peninsula were mosaiced and clipped using the Korean Peninsula polygon (Figure 1); regions above $1900 \mathrm{~m}$ were classified as plateau vegetation as per Kong et al. [39] and identified using GEP. 


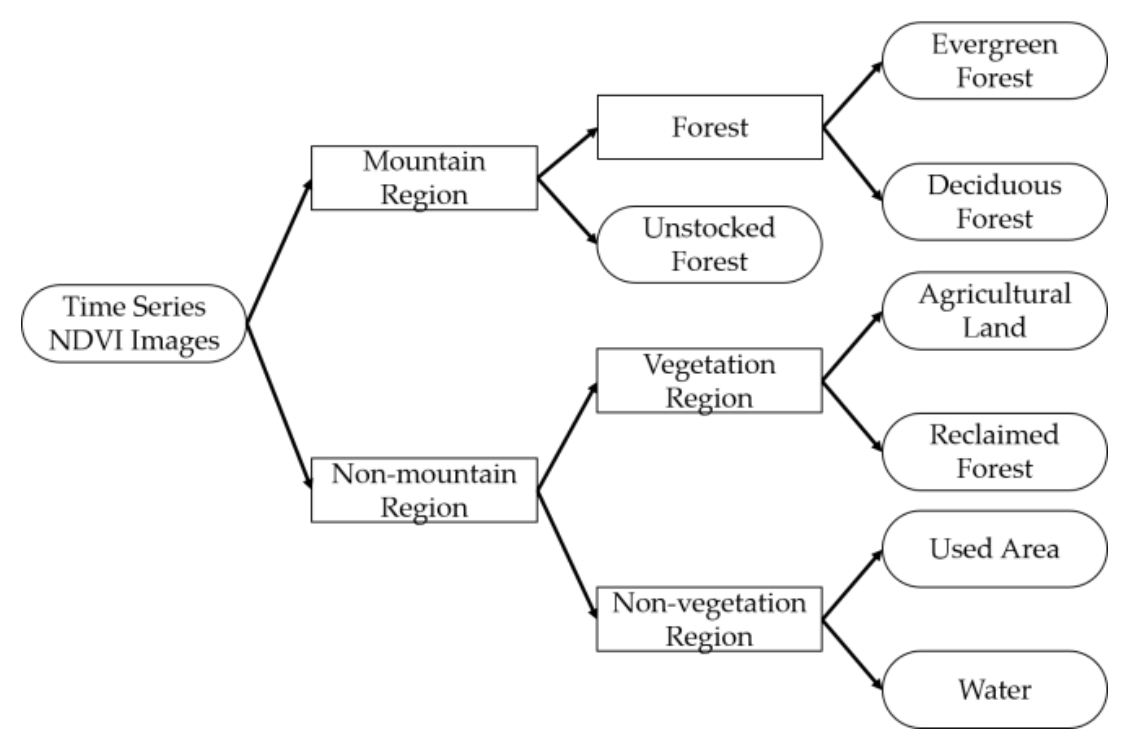

Figure 6. Stepwise classification process.

The priority afforestation areas were identified from the classification results; these areas reflected the most effective afforestation sites in North Korea. Effective afforestation criteria differed based various factors including the soil type, weather and forest type. The National Institute of Forest Science of South Korea has been monitoring forested and deforested areas in North Korea every 10 years, beginning in 1999. They define target afforestation sites as sites a slope $>8^{\circ}$, as per the Agricultural Land Act of South Korea [7]. North Korea reported that areas with a slope $>15^{\circ}$ were regarded as afforestation target sites based on the agroforestry policy data of North Korea, procured during a 2015 international workshop [7]. Yu et al. [40] demonstrated that the soils in North Korea are relatively dry; as such, applying the slope $>8^{\circ}$ criteria for target sites is desirable for the afforestation of North Korea [40]. Afforestation areas with slopes $>8^{\circ}$ may be compared with the past materials. Thus, deforested areas with slopes $>8^{\circ}$ were extracted by applying those criteria from SRTM DEM data. Deforested areas with slopes $>15^{\circ}$ were also extracted to evaluate the agroforestry policy of North Korea. For effective forest restoration, the priorities of afforestation sites were established; these priorities were set at five grades, and additionally difficult areas for reforestation were set as natural restoration targets. The afforestation priority was initially graded based on the type of deforestation, followed by slope. Each slope standard was established through reforestation-related studies $[40,41]$ in Korea.

\section{Results and Discussion}

\subsection{Land Classification Results and Accuracy Verification}

North Korean land cover was classified into five macro-classes and eight sub-classes (Figure 7), based on the classification results using the U-Net algorithm and the phenological characteristics of vegetation. Reclaimed forest was included in the agricultural area, as it is essentially used as agricultural land. Furthermore, unstocked forest is included in area of forest, as it was forest, but deforested.

To accurately verify the results, 990 points were randomly scattered and visually interpreted and identified using GEP data and Figure 4. The confusion matrix was derived from the visual interpretation results in Table 1 . The classification accuracy was $84.8 \%$ and the kappa value was 0.7740 ; these exceed the standards for securing a $75 \%$ classification accuracy [42].

Based on the spatial distribution of the classification results, the agricultural land was largely distributed in the west. The plateau vegetation, extracted using DEM, was distributed in the Ryanggang and Hamgyong provinces, where the Kaema Plateau is located. Notably, the deforested areas were distributed at the boundary between forest and agricultural lands at low altitude. This spatial distribution reflects the characteristics of 
deforestation caused by the human reclamation of forest. Table 2 shows that the total area of agriculture is the sum of agricultural land and reclaimed forest, which is approximately $35 \%$ of North Korean territory. By contrast, $18 \%$ of South Korea is agricultural land, which means that North Korea is using a large area for agriculture due to food shortages.

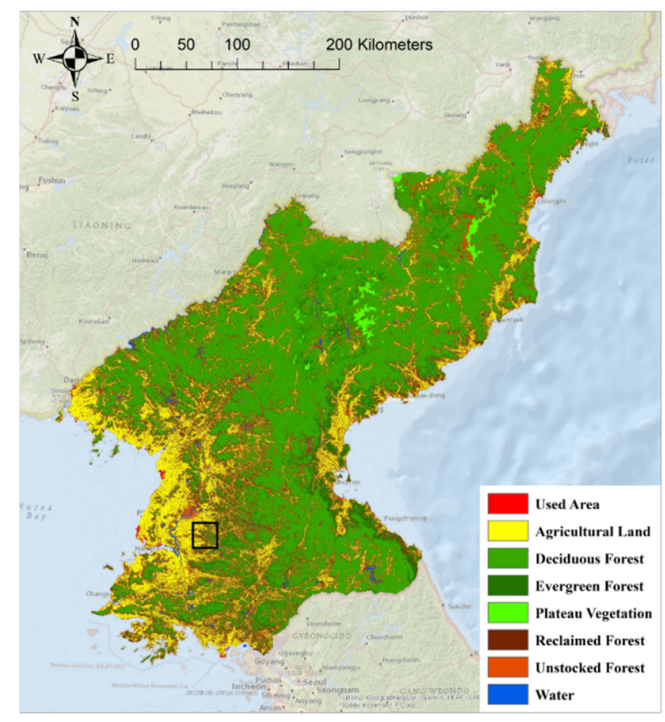

(a)

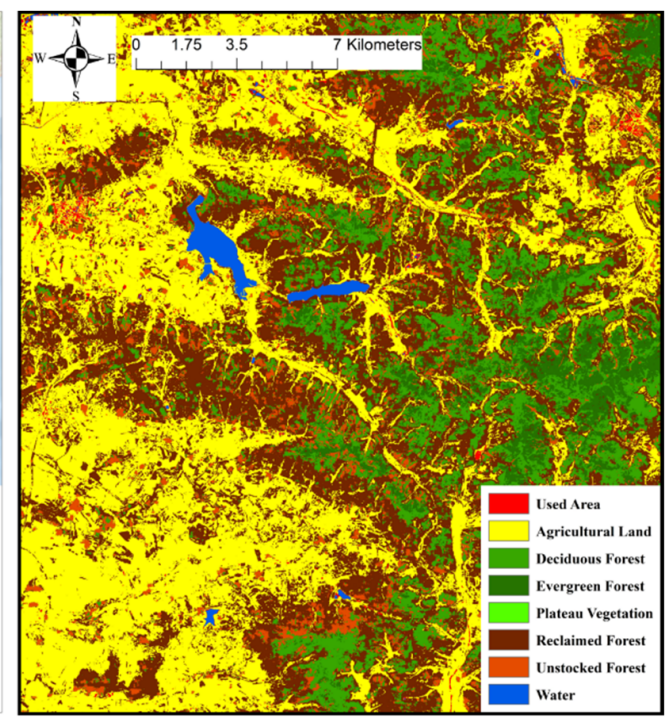

(b)

Figure 7. U-Net based vegetation phenological classification of North Korea: (a) land cover map of North Korea; and (b) detailed view of the Pyongyang region.

Table 1. Confusion matrix for the land cover classification of North Korea.

\begin{tabular}{|c|c|c|c|c|c|c|c|c|c|c|}
\hline & $\begin{array}{l}\text { Used } \\
\text { Area }\end{array}$ & Agriculture & Deciduous & Evergreen & Plateau & Reclaimed & Unstocked & Water & Total & UA \\
\hline Used Area & 2 & 1 & 1 & 1 & 0 & 0 & 0 & 8 & 13 & $15.4 \%$ \\
\hline Agriculture & 4 & 139 & 0 & 0 & 0 & 35 & 0 & 0 & 178 & $78.1 \%$ \\
\hline Deciduous & 0 & 3 & 484 & 26 & 0 & 3 & 1 & 0 & 517 & $93.6 \%$ \\
\hline Evergreen & 0 & 0 & 0 & 47 & 0 & 0 & 0 & 0 & 47 & $100 \%$ \\
\hline Plateau & 0 & 0 & 0 & 0 & 10 & 0 & 0 & 0 & 10 & $100 \%$ \\
\hline Reclaimed & 6 & 12 & 16 & 14 & 0 & 125 & 3 & 0 & 176 & $71 \%$ \\
\hline Unstocked & 0 & 3 & 0 & 6 & 0 & 6 & 24 & 0 & 39 & $61.5 \%$ \\
\hline Water & 1 & 0 & 0 & 0 & 0 & 0 & 0 & 9 & 10 & $90 \%$ \\
\hline Total & 13 & 158 & 501 & 94 & 10 & 169 & 28 & 17 & 990 & \\
\hline PA & $15.4 \%$ & $88.0 \%$ & $96.6 \%$ & $50 \%$ & $100 \%$ & $74.0 \%$ & $85.7 \%$ & $52.9 \%$ & & $84.8 \%$ \\
\hline
\end{tabular}

UA: User's Accuracy; PA: Producer's Accuracy; Accuracy: 84.8\%. Kappa: 0.7740.

The classification results were used to calculate the deforestation ratio according to administrative districts, as shown in Table 3. The deforestation ratio in the southwest region including the Pyongan and Hwanghae provinces, was higher (maximum of 61\%), compared to the northeast region including the Hamgyong, Chagang, and Ryanggang provinces. As the southwest region is an area with a high proportion of agricultural land, forests may have been reclaimed to further expand agricultural land.

The agricultural land and forest areas differed when comparing the results of this study and the land cover map from the Korean Ministry of Environment (Table 2). However, the total agricultural land and forest areas were very close (i.e., 11.3 and 11.5 million ha). This error may have occurred as researchers used different criteria to classify the land cover; the FAO reported that the forested area of North Korea was 9 million ha in 1987 [34], while the Korean Rural Economic Institute (KREI) reported that the agriculture area of North Korea is 1.96 million ha in 2009 [16]. As such, in terms of the reports from the FAO and KREI on land cover change over time, this study includes deforested areas within forest area, and the classification results are convincing. 
Table 2. Area calculation of classification results and comparison.

\begin{tabular}{cccc}
\hline Macro-Class & Sub-Class & $\begin{array}{c}\text { Classification } \\
\text { Results (ha) }\end{array}$ & $\begin{array}{c}\text { Korean Ministry of } \\
\text { Environment (ha) }\end{array}$ \\
\hline Used Area & Used Area & 160,536 & 201,404 \\
\hline \multirow{2}{*}{ Agricultural Land } & Agricultural Land & $2,164,308$ & - \\
& Reclaimed Forest & $2,137,396$ & - \\
& Total & $4,301,703$ & $3,072,785$ \\
\hline \multirow{2}{*}{ Forest } & Deciduous Forest & $6,451,421$ & - \\
& Evergreen Forest & 573,256 & - \\
& Unstocked Forest & 472,912 & - \\
& Total & $7,024,677$ & $2,503,797$ \\
\hline \multirow{2}{*}{ Grass } & Plateau Vegetation & 118,515 & - \\
& Grass & - & 38,020 \\
\hline Wet Land & Wet Land & - & 150,632 \\
\hline Barren & Barren & - & 166,835 \\
\hline Water & Water & 80,097 & $12,160,697$ \\
\hline Total Area & & $12,158,440$ &
\end{tabular}

Table 3. Spatial distribution of classification results by province.

\begin{tabular}{cccc}
\hline Province & Forested Area & Deforested Area & $\begin{array}{c}\text { Deforestation } \\
\text { Ratio }\end{array}$ \\
\hline Pyongyang capital city & 50,710 & 88,667 & $64 \%$ \\
Rason special city & 50,419 & 18,728 & $27 \%$ \\
Nampho special city & 5513 & 27,641 & $83 \%$ \\
Kaesong special city & 53,656 & 50,731 & $49 \%$ \\
South Pyongan & 539,814 & 274,574 & $34 \%$ \\
North Pyongan & 525,275 & 318,135 & $38 \%$ \\
Chagang & $1,164,533$ & 261,579 & $18 \%$ \\
South Hwanghae & 184,160 & 283,653 & $61 \%$ \\
North Hwanghae & 352,934 & 253,148 & $42 \%$ \\
Kangwon & 749,944 & 214,287 & $22 \%$ \\
South Hamgyong & $1,239,313$ & 319,999 & $21 \%$ \\
North Hamgyong & $1,051,034$ & 278,154 & $21 \%$ \\
Ryanggang & $1,057,372$ & 222,750 & $17 \%$ \\
\hline Total Area & $7,024,677$ & $2,610,308$ & $27 \%$ \\
\hline
\end{tabular}

\subsection{Comparison with Previous Studies for the Deforested Area}

The area of priority afforestation sites was derived using the classification results and compared with the Statistics Korea and Jin et al. [7,14] results in Table 4. As a result of the derivation, the total area of deforestation was 2.6 million ha; this is the same as the Statistics Korea result [7]. However, the Statistics Korea result was derived by applying slopes $>8^{\circ}$, while the results from this study were derived without slope. Therefore, slope is considered in this study and compared against the Statistic Korea results, the total area of deforestation from this study is 1.7 million ha versus the 2.6 million ha [7]. For slopes $>15^{\circ}$ as per the agroforestry policy data of North Korea, the deforestation area was 1.1 and 1.4 million ha for this study and from Statistics Korea, respectively [7]. There is a difference between the results of these two studies; this may be due to the differences from the spatial resolution of the satellite images and the data acquisition time for images used. Statistics Korea classified land cover using single period RapidEye satellite imagery with $5 \mathrm{~m}$ resolution; compared with Jin et al. [14], the deforestation area is significantly different. Although this study and Jin et al. [14] classified using the phenological characteristics of vegetation, there was a large difference in the spatial resolution (i.e., 10 versus $250 \mathrm{~m}$ ) [14]. Therefore, the area of 
deforested land was overestimated as the deforested land in North Korea is distributed in small patches. Based on the spatial distribution of the classification results, the spatial distribution of deforestation is also very similar. When comparing the results of the three studies, the classification area varies depending on the resolution, as the results of this study and that from Statistics Korea were similar [7]. This emphasized the importance of using high-resolution satellite imagery to effectively analyze the deforestation area in North Korea.

Table 4. Result comparison of deforestation status.

\begin{tabular}{cccc}
\hline Class & $\begin{array}{c}\text { Classification } \\
\text { Results (ha) }\end{array}$ & $\begin{array}{c}\text { Statistics Korea } \\
\text { (ha) }\end{array}$ & $\begin{array}{c}\text { Jin et al. } \\
\text { (ha) }\end{array}$ \\
\hline Deciduous Forest (a) & $6,451,421$ & - & - \\
Evergreen Forest (b) & 573,256 & - & - \\
Reclaimed Forest (c) & $2,137,395$ & $1,217,000$ & $2,700,000$ \\
Unstocked Forest (d) & 472,912 & $1,401,000$ & $1,300,000$ \\
Healthy Forest (a) + (b) & $7,024,677$ & $6,767,000$ & $8,300,000$ \\
Deforested Land (c) +(d) & $2,610,308$ & $2,618,000$ & $4,000,000$ \\
Total Forest (a) + (b) + (c) + (d) & $9,634,985$ & $9,386,000$ & $11,695,905$ \\
\hline Deforestation Ratio & $27.1 \%$ & $28 \%$ & $34.2 \%$ \\
Priority Afforestation Site $\left(\mathbf{8}^{\circ}<\right)$ & $1,709,618$ & $2,618,000$ & \\
Priority Afforestation Site $\left(\mathbf{1 5}^{\circ}<\right)$ & $1,124,194$ & $1,475,000$ & - \\
\hline
\end{tabular}

\subsection{Identification of Priority Afforestation Target Site}

The priority afforestation target sites were graded in Table 5 and mapped in Figure 8 in order ensure effective restoration and identify effective sites in North Korea. Reclaimed forest and unstocked forest of Figure 7 are graded using slope and altitude data derived from STRM DEM. According to the results of a study by the KREI for afforestation in North Korea, it is difficult to proceed with the project due to poor accessibility in areas with an altitude exceeding $600 \mathrm{~m}$ [41]. As such, it is necessary to prevent the further destruction of forests by human activity and restore forests through the natural transition process in deforested lands at altitudes $>600 \mathrm{~m}$. Among the deforested areas in North Korea, the area with the first grade for afforestation were the unstocked forests at altitudes $<600 \mathrm{~m}$. Unstocked forests make up less than $30 \%$ of the crown area and are suitable for reforestation as it is essentially a forest physiognomy where vegetation grows in a natural state. Compared to reclaimed forests, unstocked forests have better soil physical and chemical conditions as crops are not continuously grown in these areas. Afforestation priorities two to five were prioritized based on the slope of reclaimed forests at altitudes $<600 \mathrm{~m}$; the higher the slope, the greater the priority, and the more difficult it is for crop cultivation which increases the risk of soil erosion. In North Korea, it is desirable to continue using reclaimed forests used as agricultural land as an agroforestry policy until energy and food resources are secured; this is because it is the lack of energy and food security that is driving the deforestation in forests of North Korea. Areas with a slope $>20^{\circ}$ (the second grade), have a high risk of soil erosion, as such, forest restoration through the Afforestation and Reforestation Clean Development Mechanism (A/R CDM) project is required [41]. The slope criteria for the third grade were set at $15^{\circ}$, which is the lower limit of the $15^{\circ}$ to $30^{\circ}$ slope range; the standard as per the North Korean agroforestry policy. The rationale for setting the lower limit of $8^{\circ}$ for the fourth grade, was based on the research results of Yu et al. [40] and the Korean Agricultural Land Law. The last fifth grade area was an area with a slope $<8^{\circ}$; this area may be afforested when all energy and agricultural resource problems are resolved. As such, the restoration of forests in North Korea is a very complex problem that must consider the scientific aspects of forest ecosystems, and socio-economic issues such as energy and food resources [41]. The restoration of forests is extremely challenging for the North Korea to achieve independently; thus, forestry cooperation of the Republic of Korea and the international communities is necessary $[9,29,30]$. 
Table 5. Afforestation priority grade.

\begin{tabular}{ccc}
\hline Afforestation Priority Grade & Description & Area (ha) \\
\hline Grade 1 & Unstocked forests with altitudes $<600 \mathrm{~m}$ & 258,304 \\
Grade 2 & Reclaimed forest with slope $>20^{\circ}$ & 293,535 \\
Grade 3 & Reclaimed forest with slope $15^{\circ}-20^{\circ}$ & 286,648 \\
Grade 4 & Reclaimed forest with slope $8^{\circ}-15^{\circ}$ & 577,564 \\
Grade 5 & Reclaimed forest with slope $0^{\circ}-8^{\circ}$ & 721,289 \\
Natural restoration area & Deforested areas with altitudes $>600 \mathrm{~m}$ & 472,967 \\
\hline Total Area & & $2,610,308$ \\
\hline
\end{tabular}

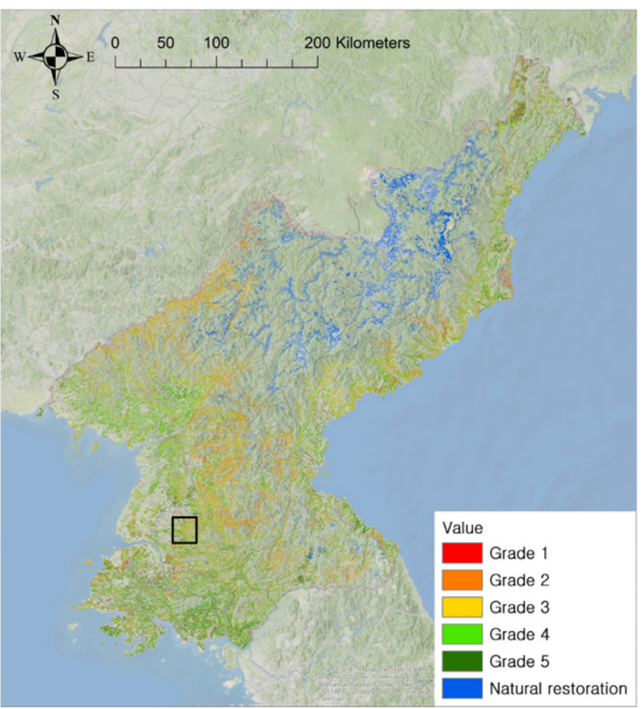

(a)

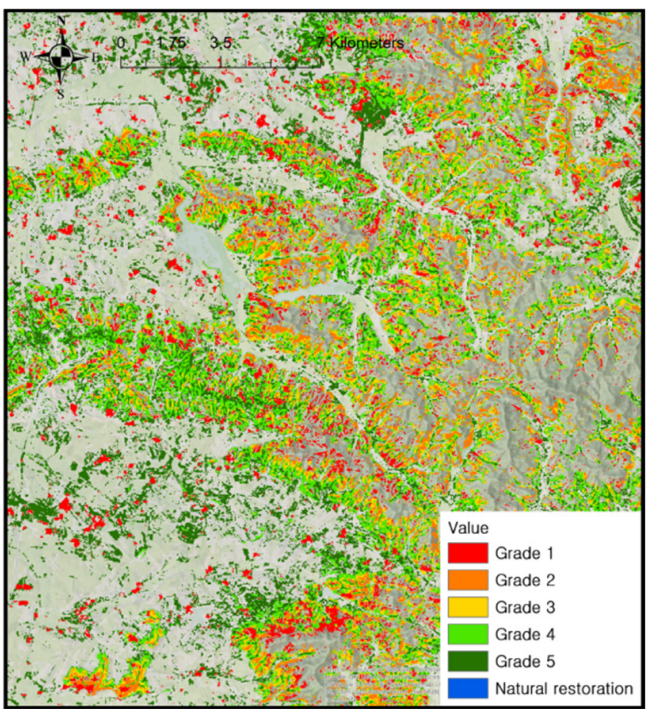

(b)

Figure 8. Mapping the afforestation priority grades in North Korea: (a) whole of North Korea; and (b) detailed view for the Pyongyang region.

\subsection{Implication of Phenological Classification with Sentinel Satellite and Deep Learning Algorithm}

To identify the deforestation area in North Korea and determine target sites for priority afforestation, the phenological characteristics of vegetation were used to reflect the deforestation characteristics in North Korea. The derived phenological characteristics of vegetation were reflected in five scenes that were learned, resulting in high-accuracy classification results. These results confirmed that phenological features according to vegetation cover may appear in time-series satellite imagery and can be learned by the classification algorithm. As such the Sentinel-2 satellite imagery, which can acquire sufficient number of images due to its short visit period, was suitable for this methodology. This imagery has a spatial resolution of $10 \mathrm{~m}$, which indicates its ability to reflect the characteristics of the small, patch-like deforestation that occurs in North Korea. Those imagery enabled confirmation of the area and spatial distribution of deforested land, and the spatial derivation of effective afforestation target sites.

By using a deep learning algorithm and a stepwise classification methodology, we were able to overcome limitations posed by the lack of labeling data. If high-accuracy labeling data exists, the land cover of North Korea may be more effectively classified with deep learning; however, field investigations are difficult due to due to limited accessibility of these areas. As such, precise classification using deep learning and high-resolution satellite imagery was feasible. Due to the high resolution of Sentinel-2 satellite imagery, the images covering all of North Korea is very huge data; this allowed for very high classification accuracy as the deep learning algorithm is suitable for big data analysis. Thus, it was possible to map North Korean land cover with high accuracy. However, a major 
limitation is that unpaved roads, small farmland or green areas in cities are classified as agricultural land, forest, on used area.

This multi-series vegetation phenological classification methodology enables the mapping of land cover on an annual basis. As such, it is possible to effectively track changes in forests in the Korean Peninsula, including North Korea and regions with similar climatic zones; using this data, it is possible to estimate the carbon uptake of forests.

\section{Conclusions}

A thorough classification of land cover and deforested areas using phenological characteristics and the deep learning technique has significant implications for afforestation in North Korea. The land cover of North Korea was classified with an accuracy of $84.8 \%$, producing results similar to those of previous studies. this study derived a total of 2.6 million ha of afforestation sites, which were graded to enable effective afforestation and forest restoration. The application of deep learning algorithms for big data analysis of shortperiod, high-resolution satellite imagery was very effective. Though U-Net algorithm demands labeled data for training, the histogram threshold supplementing the lack of labeling data, and the classification accuracy demonstrates the adequacy of this method. A major limitation is that objectivity is not secured; every data is remotely sensed and visually interpreted and identified. Using the classification methodology of this study, it was easy to classify land cover in temperate areas with clear seasonal changes and high vegetative cover. As the phenological characteristics of vegetation appear on a yearly basis, land cover maps may be updated annually, enabling the effective tracking of land cover change.

As deforestation has been ongoing for many years in North Korea, it is necessary to track changes in land cover and forested areas. Using the methodology present in this study, land cover maps may be established on an annual basis, enabling the tracking of changes. If afforestation is carried out in stages based on the priority results from this study, the effect of afforestation is maximized and the potentiation for re-deforestation of afforested sites is low. If the forest area is expanded and the forest ecosystem is restored through successful afforestation, this may improve the overall ecosystem services in North Korea.

Author Contributions: Conceptualization, C.-H.L.; methodology, J.K.; investigation, J.K.; data curation, H.-W.J.; writing-original draft preparation, J.K.; writing-review and editing, C.-H.L. and H.-W.J.; supervision, W.-K.L.; funding acquisition, W.-K.L. All authors have read and agreed to the published version of the manuscript.

Funding: This research was funded by National Research Foundation of Korea grant of the Ministry of Science and ICT (No. 2019R1C1C1004979), and Korea University grant.

Institutional Review Board Statement: Not applicable.

Informed Consent Statement: Not applicable.

Data Availability Statement: Not applicable.

Acknowledgments: The authors gratefully acknowledge the support of the OJEong Resilience Institute (OJERI) at Korea University and Division of Environmental Science and Ecological Engineering, Korea University, grant number K2106681.

Conflicts of Interest: The authors declare no conflict of interest.

\section{References}

1. Díaz, S.; Hector, A.; Wardle, D.A. Biodiversity in forest carbon sequestration initiatives: Not just a side benefit. Curr. Opin. Environ. Sustain. 2009, 1, 55-60. [CrossRef]

2. Pan, Y.; Birdsey, R.A.; Fang, J.; Houghton, R.; Kauppi, P.E.; Kurz, W.A.; Phillips, O.L.; Shvidenko, A.; Lewis, S.L.; Canadell, J.G.; et al. A large and persistent carbon sink in the world's forests. Science 2011, 333, 988-993. [CrossRef]

3. Sedjo, R.; Sohngen, B. Carbon sequestration in forests and soils. Annu. Rev. Resour. Econ. 2012, 4, 127-144. [CrossRef]

4. Moura-Costa, P. Tropical Foestry Practices for Carbon Dequestration. Dipterocarp Forest Ecosystems: Towards Sustainable Management; World Scientific: Singapore, 1996; p. 309.

5. Lee, S.J.; Lim, J.S.; Kang, J.T. Standard carbon uptake of major forest species (ver.1.2). NIFoS For. Policy Issue 2019, $129,13$. 
6. Korea Forest Service. Available online: https://www.forest.go.kr/ (accessed on 1 June 2021).

7. Yang, A.R.; Kim, K.M.; Lim, J.B.; Kim, E.H. Analysis of North Korea's Forest Change Using Satellite Imagery. North Korea's Main Stat. Indic. 2020, 25, 239-253.

8. E-National Index. Available online: https://www.index.go.kr/ (accessed on 1 June 2021).

9. Choi, H. Prospect and Implementation Strategy of the Inter-Korean Forest Cooperation: A case study of international organization support project in DPRK. Unificaiton Policy Stud. 2018, 27, 1-20.

10. Global Forest Watch. Available online: https:/ / www.globalforestwatch.org/ (accessed on 1 June 2021).

11. Yeom, J.M.; Han, K.S.; Lee, C.S.; Park, Y.Y.; Kim, Y.S. A Detection of Vegetation Variation Over North Korea using SPOT/VEGETATION NDVI. J. Korean Assoc. Geogr. Inf. Stud. 2008, 11, $28-37$.

12. Oh, C.Y.; Park, S.Y.; Kim, H.S.; Lee, Y.W.; Choi, C.U. Comparison of Landcover Map Accuracy Using High Resolution Satellite Imagery. J. Korean Assoc. Geogr. Inf. Stud. 2010, 13, 89-100.

13. Jeong, S.G.; Park, J.; Park, C.H.; Lee, D.K. Terrace fields classification in North Korea using MODIS multi-temporal image data. J. Korean Soc. Environ. Restor. Technol. 2016, 19, 73-83. [CrossRef]

14. Jin, Y.; Sung, S.; Lee, D.K.; Biging, G.S.; Jeong, S. Mapping Deforestation in North Korea Using Phenology-Based Multi-Index and Random Forest. Remote Sens. 2016, 8, 997. [CrossRef]

15. Hong, S.Y.; Rim, S.K.; Lee, S.H.; Lee, J.C.; Kim, Y.H. Spatial Anaylsis of Agro-Environment of North Korea Using Remote Sensing, I. Landcover Classification from Landsat TM imagery and Topography Analysis in North Korea. Korean J. Environ. Agric. 2008, 27, 120-132. [CrossRef]

16. Park, K.S. Focus; Forest Status and Forest Policy in North Korea. KREI North Korean Agric. Trends 2013, 15, 1-21.

17. The National Atlas of Korea. Available online: http:/ / nationalatlas.ngii.go.kr/ (accessed on 1 June 2021).

18. Park, S.Y.; Park, K.S.; Lee, S.Y. Forest Administrative Organization of North Korea and Characteristics of Forest Work. North Korean Stud. 2009, 4, 75-101.

19. Kim, D.; Lim, C.H.; Song, C.; Lee, W.K.; Piao, D.; Heo, S.; Jeon, S. Estimation of future carbon budget with climate change and reforestation scenario in North Korea. Advances in Space Research 2016, 58, 1002-1016. [CrossRef]

20. Lim, C.H.; Song, C.; Choi, Y.; Jeon, S.W.; Lee, W.K. Decoupling of forest water supply and agricultural water demand attributable to deforestation in North Korea. J. Environ. Manag. 2019, 248, 109256. [CrossRef] [PubMed]

21. Kim, Y.H. The Study Directions of NK's Food Rights and Duties. Humanit. Unification 2014, 60, 307-336. [CrossRef]

22. Foody, G.M. Status of land cover classification accuracy assessment. Remote Sens. Environ. 2002, 80, 185-201. [CrossRef]

23. Huang, X.; Lu, Q.; Zhang, L. A multi-index learning approach for classification of high-resolution remotely sensed images over urban areas. ISPRS J. Photogramm. Remote Sens. 2014, 90, 36-48. [CrossRef]

24. Liu, C.; Wei, S.; Chunxia, L.; Jianxin, X. Spatial-temporal Hidden Markov Model for Land Cover Classification using Multitemporal Satellite Images. IEEE Access 2021, 9, 76493-76502. [CrossRef]

25. Park, H.L.; Choi, J.W.; Oh, J.H. Seasonal effects removal of unsupervised change detection based multitemporal imagery. J. Korean Soc. Surv. Geod. Photogramm. Cartogr. 2018, 36, 51-58.

26. Ulmas, P.; Liiv, I. Segmentation of satellite imagery using u-net models for land cover classification. arXiv 2020, arXiv:2003.02899. Available online: https: / /arxiv.org/abs/2003.02899 (accessed on 1 June 2021).

27. Lee, S.H.; Lee, M.J. A Study on Deep Learning Optimization by Land Cover Classification Item Using Satellite Imagery. Korean J. Remote Sens. 2020, 36, 1591-1604.

28. Vali, A.; Comai, S.; Matteucci, M. Deep Learning for Land Use and Land Cover Classification Based on Hyperspectral and Multispectral Earth Observation Data: A Review. Remote Sensing 2020, 12, 2495. [CrossRef]

29. Kim, G.S.; Lim, C.-H.; Kim, S.J.; Lee, J.; Son, Y.; Lee, W.-K. Effect of National-Scale Afforestation on Forest Water Supply and Soil Loss in South Korea, 1971-2010. Sustainability 2017, 9, 1017. [CrossRef]

30. Lee, J.; Lim, C.H.; Kim, G.S.; Markandya, A.; Chowdhury, S.; Kim, S.J.; Son, Y. Economic viability of the national-scale forestation program: The case of success in the Republic of Korea. Ecosyst. Serv. 2018, 29, 40-46. [CrossRef]

31. Lee, S.; Choi, H.A.; Yoo, H.; Song, C.; Cha, S.; Bae, S.W.; Son, Y.; Lee, W.K. Restoration Plan for Degraded Forest in The Democratic People's Republic of Korea Considering Suitable Tree Species and Spatial Distribution. Sustainability 2018, 10, 856. [CrossRef]

32. Kang, S.; Choi, W. Forest cover changes in North Korea since the 1980s. Reg. Environ. Chang. 2014, 14, 347-354. [CrossRef]

33. Lim, C.H.; Choi, Y.; Kim, M.; Jeon, S.W.; Lee, W.K. Impact of deforestation on agro-environmental variables in cropland, North Korea. Sustainability 2017, 9, 1354. [CrossRef]

34. Food and Agriculture Organization of the United Nations (FAO). Available online: http:/ / www.fao.org/ (accessed on 1 June 2021).

35. Heo, S.H. Searching for the Inter-Korean Forest Cooperation Considering Forest Restoration Strategy and limits of Kim Jong-un Era: Focusing on Literature Review and Experts Interview. J. North Korea Stud. 2020, 6, 69-92.

36. Oh, S.U.; Kim, E.H.; Kim, K.M. Characteristics of forest policy in the Kim Jong-Un era. North Korean Stud. 2018, 14, 101-133.

37. Ronneberger, O.; Fischer, P.; Brox, T. U-net: Convolutional networks for biomedical image segmentation. In International Conference on Medical image computing and computer-assisted intervention; Springer: Cham, Switzerland, 2015; pp. $234-241$.

38. Otsu, N. A threshold selection method from gray-level histograms. IEEE Trans. Syst. ManCybern. 1979, 9, 62-66. [CrossRef]

39. Kong, W.S. Biogeographic feature of North Korean ecosystem. J. Environ. Impact Assess. 2002, 11, 157-172.

40. Yu, J.; Park, H.; Lee, S.H.; Kim, K.M. Review of Slope Criteria and Forestland Restoration Plan in North Korea. J. Korean Soc. Environ. Restor. 2016, 19, 19-28. 
41. Seok, H.D.; Kim, Y.H.; Lee, Y.H.; Koo, J.C.; Park, S.H.; Lee, C.H.; Yoon, T.S. The Strategy of the Restoration and Conservation of Deforested and Degraded Mountainous Areas in North Korea; KREI: Naju, Korea, 2014; p. 23.

42. Environmental Spatial Data Service. Available online: https:/ / egis.me.go.kr/main.do (accessed on 1 June 2021). 